\title{
TOXICIDADE DE ÓLEOS ESSENCIAIS PARA O CONTROLE DE Tetranychus urticae KOCH, 1836 (ACARI: TETRANYCHIDAE)
}

\author{
Camila Santos Teixeira ${ }^{1}$ \\ Camila Costabeber Nunes ${ }^{2}$ \\ Romário Vargas ${ }^{3}$ \\ José Romário de Carvalho ${ }^{4}$ \\ Hugo Bolsoni Zago ${ }^{5}$
}

\begin{abstract}
Resumo: O ácaro rajado é considerado uma importante praga agrícola, causando danos em diferentes cultivos. O controle à base de acaricidas químicos pode vir a causar problemas ambientais e à saúde do homem. Desta forma o uso de óleos essenciais obtidos de produtos botânicos é uma alternativa no controle de pragas por apresentar baixo efeito residual, sendo objetivo deste trabalho avaliar a mortalidade e o efeito na fertilidade de fêmeas adultas de Tetranychus urticae submetidas a tratamentos com óleos essenciais de laranja doce e limoneno, fornecidos pela empresa Ferquima Indústria e Comércio LTDA., e pela empresa Pack Indústria e Comércio de Produtos Agropecuários LTDA., respectivamente. Para avaliar a ação fumigante do óleo essencial sobre os ácaros foram realizados testes submetendo fêmeas adultas de $T$. urticae à dose pura do óleo essencial utilizando as dosagens de 5, 15 e $25 \mu \mathrm{L}$ em câmaras de fumigação. Após o período de exposição ao óleo foi contabilizado o número de ácaros mortos e a quantidade de ovos depositados. Os resultados não foram significativos para mortalidade e para fertilidade de fêmeas adultas de T. urticae.
\end{abstract}

Palavras-chave: Ácaro rajado; Óleo essencial; Controle alternativo.

\footnotetext{
${ }^{1}$ Centro de Ciências Agrárias e Engenharias/Departamento de Produção Vegetal/ Universidade Federal do Espírito Santo, Brasil. E-mail: teixeira.camila@outlook.com.

2 Centro de Ciências Agrárias e Engenharias/Departamento de Produção Vegetal/ Universidade Federal do Espírito Santo, Brasil. E-mail: camila.costabeber@hotmail.com.

3 Centro de Ciências Agrárias e Engenharias/Departamento de Produção Vegetal/ Universidade Federal do Espírito Santo, Brasil. E-mail: romariovg9@gmail.com.

4 Centro de Ciências Agrárias e Engenharias/Departamento de Produção Vegetal/ Universidade Federal do Espírito Santo, Brasil. E-mail: jromario_carvalho@hotmail.com.

5 Centro de Ciências Agrárias e Engenharias/Departamento de Produção Vegetal/ Universidade Federal do Espírito Santo, Brasil. E-mail: hugozago@gmail.com.
} 